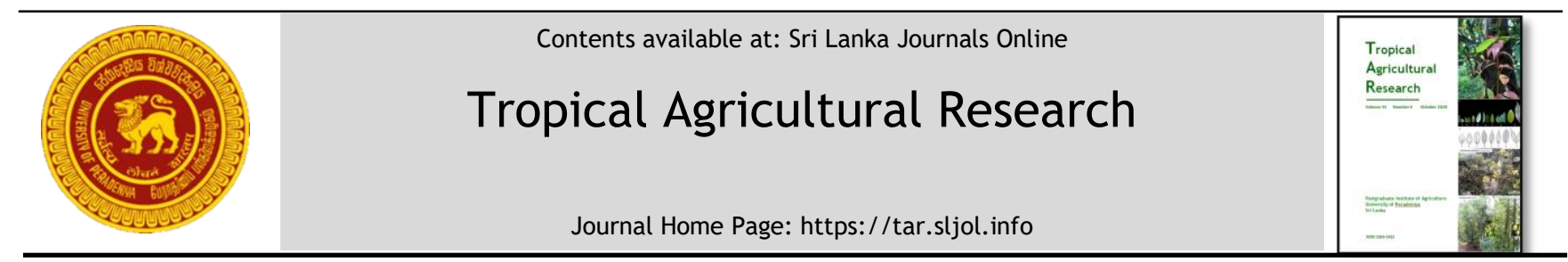

\title{
Physico-Chemical Properties of Sri Lankan Instant Black Tea Manufactured Using Broken Mixed Fannings (BMF) as Raw Materials Obtained from Different Estates of Three Elevation Categories
}

\author{
K.A.P. Dalpathadu ${ }^{1,2^{*}}$, S.P. Nissanka ${ }^{3}$ and C.V.L. Jayasinghe ${ }^{4}$ \\ ${ }_{1}$ Martin Bauer Hayleys (Pvt) Ltd, Blinkbonnie Estate, Dickoya, Sri Lanka \\ ${ }^{2}$ Postgraduate Institute of Agriculture, University of Peradeniya, Peradeniya, Sri Lanka \\ ${ }^{3}$ Department of Crop Science, Faculty of Agriculture, University of Peradeniya, Peradeniya, Sri Lanka \\ ${ }^{4}$ Department of Food Science and Technology, Faculty of Livestock, Fisheries and Nutrition, Wayamba University of Sri \\ Lanka, Makandura, Gonawilla, Sri Lanka
}

\section{ARTICLE INFO}

\section{Article history:}

Received: 14 August 2019

Accepted: 11 November 2019

Revised version received: 28 September 2020

Available online: 1 October 2020

\section{Keywords:}

Paddy

Phosphorus

Potassium

Variability

Yield Response

\section{Citation:}

Dalpathadu K.A.P., Nissanka S.P. and Jayasinghe C.V.L. (2020). Physicochemical properties of Sri Lankan instant black tea manufactured using broken mixed fannings (BMF) as raw materials obtained from different estates of three elevation categories. Tropical Agricultural Research, 31(4): 91-100.

DOI: http://doi.org/10.4038/tar.v31i4.8423

Dalpathadu K.A.P. id

https://orcid.org/0000-0002-0600-0680

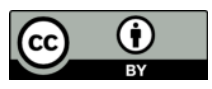

*Corresponding author : akiladalpe@gmail.com

\section{ABSTRACT}

Production of instant tea, which is used as a colorant and a beverage ingredient, is a growing industry in the world. Refuse tea is industrially identified as Broken Mixed Fannings (BMF) and is a primary raw material for instant tea production due to its cost-effectiveness. This study was carried out to assess the quality variation of BMF obtained from tea estates of different elevation categories and instant black tea powder produced from these BMF types to explore opportunities to produce instant tea types that customers prefer. BMF samples were collected from ten different estates, representing the elevation categories of up (LC), mid (MC) and low (LC) country of Sri Lanka. Total antioxidant activity (TAA), total polyphenol (TPC), caffeine and moisture contents, colour, haze and $\mathrm{pH}$ of both BMF and instant tea powder were analysed using standard methods. Though significant differences were not observed among elevation categories for the parameters of colour, $\mathrm{pH}$, contents of moisture, caffeine, TPC and TAA for both BMF and instant tea, there were significant variations in these parameters among estates. TPP content was highest in Halgolla of LC (18.5\%) and lowest in Deniyaya of MC (10.1\%). There was a significant difference in haze value of up country BMF (38.5 NTU) and the instant tea produced from them (138 NTU), compared to mid and low elevation categories. The highest caffeine contents for both BMF and instant tea were observed from low country estates. In average, TAA content was increased by three-folds and TPC content by two-folds when instant tea powder was produced from BMF. Therefore, the quality variations of instant tea types produced from BMF of different estates of elevation categories revealed the possibility of formulating required quality and healthy products based on customer preference by selecting proper combinations and proportions from known sources of raw materials. 


\section{INTRODUCTION}

Tea (Camellia sinensis (L.) O. Kuntze) is one of the most popular non-alcoholic and aromatic beverages which has specific organoleptic characteristics (taste, aroma and colour), and health benefits. China, India, Sri Lanka, Kenya and Indonesia are the principal tea producers contributing to $77 \%$ of world production and $80 \%$ global exports. Sri Lanka plays a significant role by producing about $5.3 \%$ of global tea production (Sri Lanka Tea Board, 2016).

Ireland plays a vital role in being the largest importer (93\%, equivalent to 2.0 million $\mathrm{kg}$ ) of Ceylon instant tea. USA, Greece and Australia are also the major exporter destinations of Sri Lankan instant tea. Among the different tea products, instant tea has emerged as a modest and a highly developing sector in the tea producing countries (Sri Lanka Tea Board Annual Report, 2015).

Someswararao and Srivastav (2012) defined instant tea as a tea extract powder, which consists of completely soluble solid fraction of tea. Instant tea is globally being used for preparation of several beverages, colourings, herbal pills, pharmaceuticals etc. Since the first form of instant tea which was developed in the United Kingdom in 1885, it has made an enormous attraction in the tea sector due to the variety of application avenues, low production cost and high profitability.

Instant tea is produced by the following steps: liquor extraction, filtration, removal of particles by centrifugation, concentration by reverse osmosis or using evaporators and finally drying (Arachchilage et al., 2015). However, chemical and physical properties of extracted instant tea can differ due to the differences in the raw material used for the extraction.

'Broken Mixed Fannings' or BMF is a primary raw material for instant tea production. Arachchilage et al. (2015) defined BMF as a collective term for green leaves, dhools (particles resulting from rolling of green leaf allowed to ferment), black tea and the rejected fractions in black tea manufacturing. BMF contains a large fraction of fibrous material, and lower content of the leafy material, hence has little value in traditional tea markets. Therefore, BMF can be obtained at a lower price in the industry.

Instant tea is mainly used in the RTD (ready to drink) category in minute amounts for the claim that the base is tea, and for the natural colour of tea. In instant tea there is no tea flavour and it is masked with other fruit flavours, which are sold in the global market at very competitive prices. Hence, BMF can be successfully used for the manufacture of instant teas. The quality of instant tea largely depends on the composition of BMF, which depends on type of tea cultivar and growing environment conditions. Thus, elevation is a critical factor which affects the plant growth and development, and chemical composition due to the changes in climate (rainfall, temperature, wind, and solar radiation), soil conditions and many other geographical factors.

Arachchilage et al. (2015) showed that the quality and characteristics of instant black tea produced from different raw materials vary. However, limited information is available regarding the effect of BMF produced in different elevation levels of Sri Lanka on the physicochemical characteristics of the instant tea.

Therefore, this study was designed to investigate the variation of quality characteristics of BMF obtained from tea estates of different elevation categories of up, mid and low country and the instant tea produced from these BMF types as raw materials, and to fingerprint the quality characteristics of Sri Lankan instant black tea.

\section{MATERIALS AND METHODS}

Samples of BMF were collected from Orthodox Rotorvane tea manufacturing factories from 10 representative tea estates of low (elevation 0-300 m MASL), mid (elevation 300-600 m MASL) and up country (elevation more than $600 \mathrm{~m}$ MASL) elevations of Sri Lanka. When selecting the estates, priority was given to select estates with higher extents of the cultivar TRI 2025. Up country BMF samples were collected from the Pedro, Somerset and Nuwara Eliya estates 
which represent the Nuwara Eliya (WU2a) region, and Ingestre and Robgill tea estates representing Hatton region (WU2a). BMF samples collected from Deniyaya (WM1a) and Sogama estates (WM2a) representing the mid country. Kelani and Halgolla from Yatiyantota region (WL1a), and Moragolla from Deniyaya region (WL2a) were selected as the low country estates. In order to minimize the influence of varying weather conditions two sets of composite BMF samples (5 kg) were collected at three-month intervals from each estate for analysis.

The tea liquor was extracted from different BMF samples (2kg of each) following the standard protocol of Hayleys Global Beverages (Private.) Ltd. instant tea factory at Dikoya. The extract was stored at $4^{\circ} \mathrm{C}$ and spray dried using a miniature spray drier (Model: L-8, Serial No: 7084, OhkawaraKakohki Co., Ltd., Japan) in which the chamber temperature was maintained at $350{ }^{\circ} \mathrm{C}$.

The samples of BMF and instant tea powder produced from respective BMF types were analyzed for physicochemical and antioxidant properties (Figure 1). The determination of moisture was performed according to ISO 7513 methodology (ISO, 1990). The CIE colour $\left(\mathrm{L}^{*}, \mathrm{a}^{*}\right.$, and $\mathrm{b}^{*}$ scores) was determined with a Minolta Chroma meter (Model: CM-5,
Konica Minolta Inc., Japan). For the determination of haze, $0.3 \mathrm{~g}$ of sample was mixed with $50 \mathrm{ml}$ of deionized water and 50 $\mathrm{ml}$ of citrate buffer solution ( $\mathrm{pH}$ 3.7). Then the haze of this solution was measured using a turbidity meter (Model: 2100Q USA). A pH meter (Model: pc 2700, Eutech Instruments, Singapore) was used to measure the $\mathrm{pH}$ of the same solution. The determination of TPC was performed using Folin Ciocalteu method according to ISO 14502-1 (ISO, 2005). The caffeine content was analyzed according to a standard procedure used by Hayleys Global Beverages (Pvt.) Limited, Dikoya, as follows: A $200 \mathrm{mg}$ sample was mixed with $250 \mathrm{~mL}$ of deionized water in a volumetric flask. An aliquot $(10 \mathrm{~mL})$ of this solution and $20 \mathrm{ml}$ of chloroform were transferred into a separating funnel. After mixing and allowing to settle in two layers, the chloroform layer was separated. The absorbance of the solution was read at $276 \mathrm{~nm}$ with a UV/Visible spectrophotometer (Model: evolution 201, Thermoscientific, USA) and the caffeine content was calculated using a standard curve prepared with caffeine. Total antioxidant activity (TAA) was measured using the 2, 2-diphenyl-1-picrylhydrazyl (DPPH) free radical scavenging assay method as described by Brand-Williams et al. (1995) with

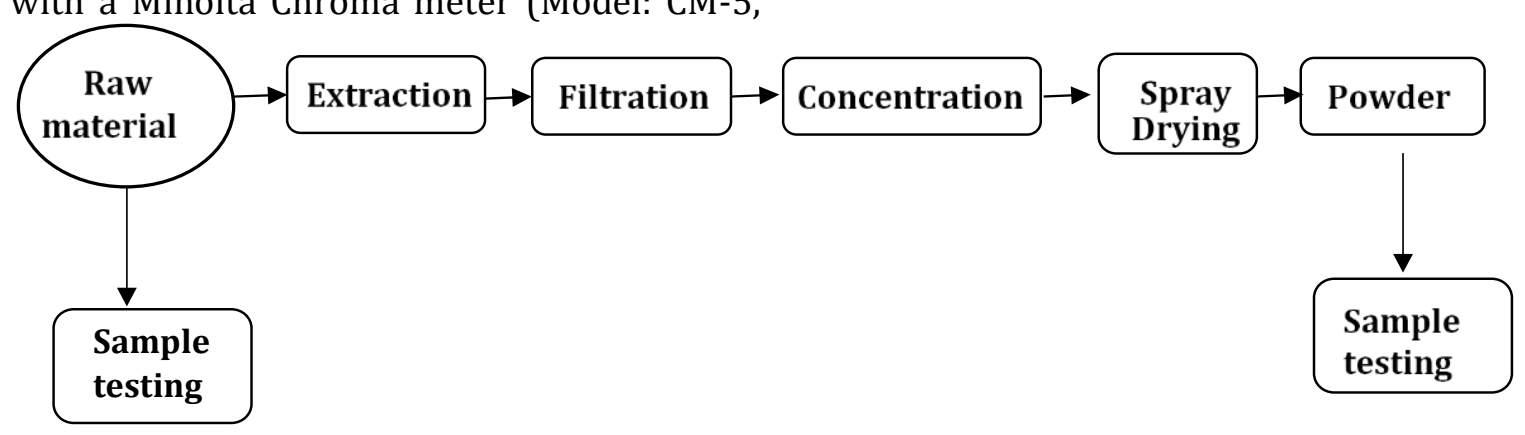

Figure 1: Process flow chart of instant tea powder production from BMF as raw materials and testing

ANOVA followed by mean separation (Duncan Multiple Range Test), was performed using SAS package to evaluate the effect of elevation factor on physicochemical properties of BMF and instant tea prepared from respective BMF.

\section{RESULTS AND DISCUSSION}

\section{Total antioxidant activity (TAA) in BMF and Instant Tea}

There was no significant difference $(p>0.05)$ in TAA contents of BMF with respect to the 
elevation categories (Figure 2a). BMF being the leftover and the coarse fraction of the tea leaves, amount of TAA is lesser than in the fine tea grades. Thus, the influence of climate and soil variations of different elevation categories had no significant effect on TAA of BMF. Kamal et al. (2008) also found that there were no significant differences for TAA of different tea grades in different elevation categories. However, Astill et al. (2001) found that variety, growing environment, manufacturing conditions, and grade (particle size) of the tea leaves influenced the quality of tea and the final infusion compositions. a

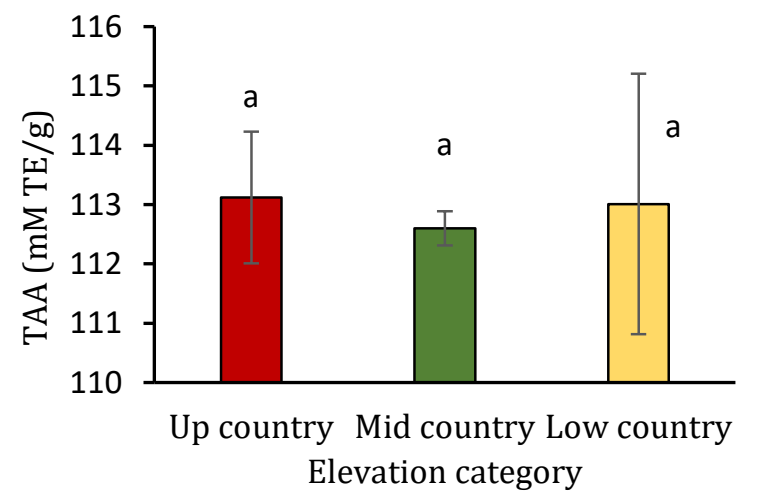

b

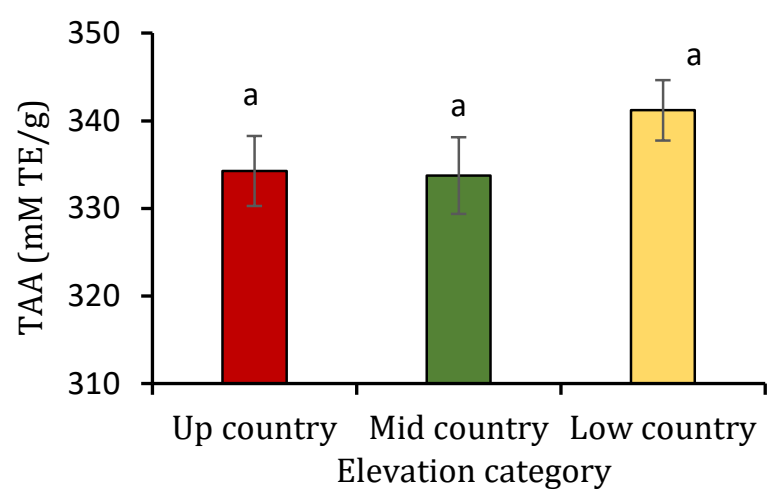

Figure 2: Variation of TAA in (a) BMF of different elevation categories, and (b) Instant tea manufactured using BMF of different elevation categories.

TAA of Instant tea across estates and elevation categories was also not significantly different (Figure 2b). The non-significant difference observed in the TAA among different elevations may be due to the high fibre content and lower content of chemical constitutes in coarse particles of the BMF, which is considered as the lowest quality tea grade.

\section{The TPC, caffeine and colour values of BMF}

The total polyphenol content (TPC), caffeine and colour values of BMF, which were obtained from the 10 different estates in the three elevation categories are shown in the Table 1.
The TPC was not significantly different among elevation categories. This may be related to the higher quality variations of estates within an elevation category due to the differences in the plucking standards and processing conditions. However, Nissanka et al. (2013) reported that TPC content of tea grades decreased when temperature decreases (elevation increases). The higher geographical elevations which have lower atmospheric temperature slows down the growth of tea plants causing leaves to develop slowly, thus, accumulating more TPC which are responsible for astringency flavour of tea infusion (Lesschaeve et al., 2005). 
Table 1: TPC, caffeine and colour of BMF of different elevation categories.

\begin{tabular}{lccccc}
\hline Estate & TPC (\%) & $\begin{array}{c}\text { Caffeine } \\
(\mathbf{m g} / \mathbf{L})\end{array}$ & $\mathbf{L}^{*}$ & $\begin{array}{c}\text { Colour } \\
\mathbf{a}^{*}\end{array}$ & $\mathbf{b}^{*}$ \\
\hline Deniyaya (MC) & 15.08 & 3.08 & 62.75 & 19.42 & 37.80 \\
Sogama (MC) & 13.21 & 3.18 & 62.34 & 17.94 & 38.76 \\
Kelani (LC) & 16.44 & 4.72 & 67.97 & 18.06 & 40.40 \\
Halgolla (LC) & 16.21 & 4.15 & 62.71 & 20.40 & 37.43 \\
Moragalla (LC) & 12.54 & 4.27 & 62.54 & 20.46 & 38.62 \\
Somerset (UC) & 11.16 & 3.25 & 68.30 & 15.89 & 40.20 \\
Ingestre (UC) & 11.66 & 3.19 & 68.91 & 17.22 & 40.93 \\
Nuwara Eliya (UC) & 13.66 & 3.07 & 73.02 & 14.59 & 42.42 \\
Pedro (UC) & 16.65 & 3.25 & 76.73 & 11.23 & 40.81 \\
Robgill (UC) & 17.57 & 3.67 & 70.45 & 16.01 & 41.01 \\
\hline
\end{tabular}

Note: LC- Low Country, MC- Mid Country and UC- Up Country $\mathrm{L}^{*}$ : lightness, $\mathrm{a}^{*}$ : Redness and $\mathrm{b}^{*}$ : Yellowness

There was also no significant difference in the caffeine content of BMF across estates and elevation categories. However, Harbowy et al. (2010) reported that the caffeine content of tea infusion may vary due to the cultivar, season, stage of plucking, geographical location, harvesting time and infusion conditions of the tea. It is also reported that tea shoots grown under shade contain more caffeine compared to those grown under the full sunlight (Song et al., 2012). Since low country has more shade trees (as high, medium and low) in tea fields with higher temperature, there is a possibility to contain higher caffeine contents in the low country BMF compared to mid and up country elevation categories. Higher caffeine contents in tea acts as a stimulant to the central nervous system, including stimulation of the respiratory, vagal and vasomotor centers in the medulla (Groisser, 2018). As a result, there is mood enhancement, a sharpening of mental clarity and vigilance, and enhancement of the higher functions of the brain, increased alertness, and a vasodilatory and stimulatory effect on cardiac muscle (Modder and Amarakoon, 2002).

The colour of tea infusion was measured in terms of $L^{*}, a^{*}, b^{*}$ values $\left(L^{*}, a^{*}, b^{*}\right.$ colour space is a 3-axis colour system with dimension $\mathrm{L}^{*}$ for lightness and $\mathrm{a}^{*}$ and $\mathrm{b}^{*}$ for the colour dimensions). Values for $L^{*}$ ranges from zero (black) to 100 (white), positive $\mathrm{a}^{*}$ is red, negative $a^{*}$ is green, positive $b^{*}$ is yellow and negative $b^{*}$ is blue. Studies of Liang et al. (2003) indicated that $\mathrm{L}^{*}$ value is negatively correlated to the quality of black tea infusion while $a^{*}$ and $b^{*}$ values are positively correlated. As per the instant tea industry, $\mathrm{L}^{*}$ value plays the major role, thus, priority was given to $L^{*}$ value of the colour.

Results of the study revealed that there was no significant difference in the colour values of BMF from the three elevation categories. Lower $L^{*}$ value indicate the dark liquor colour and the highest $\mathrm{L}^{*}$ value indicated the light liquor colour.

\section{The TPC, caffeine and colour values of instant tea}

The TPC, caffeine and colour values of instant tea produced from the BMF which were obtained from 10 estates in the three different elevation groups are presented in Table 2. Results showed that there was no significant impact on the TPC content of instant tea produced from BMF obtained from different elevation categories. 
Table 2. TPC, caffeine and colour of instant tea produced using BMF of different elevation categories

\begin{tabular}{lccccc}
\hline Estate & TPC (\%) & $\begin{array}{c}\text { Caffeine } \\
\text { (mg/L) }\end{array}$ & $\mathbf{L}^{*}$ & $\mathbf{a}^{*}$ & $\mathbf{b}^{*}$ \\
\hline Deniyaya (MC) & 29.41 & 5.76 & 67.08 & 16.38 & 37.73 \\
Sogama (MC) & 31.21 & 5.18 & 57.57 & 17.32 & 38.11 \\
Kelani (LC) & 30.15 & 6.31 & 64.85 & 16.49 & 37.26 \\
Halgolla (LC) & 29.66 & 5.80 & 61.75 & 18.11 & 34.68 \\
Moragalla (LC) & 24.45 & 6.27 & 64.24 & 18.09 & 37.79 \\
Somerset (UC) & 21.64 & 4.84 & 67.63 & 14.68 & 38.20 \\
Ingestre (UC) & 21.81 & 4.56 & 57.69 & 19.12 & 34.17 \\
N'Eliya (UC) & 24.68 & 4.66 & 64.88 & 15.77 & 38.76 \\
Pedro (UC) & 23.54 & 4.77 & 70.16 & 12.16 & 41.62 \\
Robgill (UC) & 22.91 & 4.80 & 57.59 & 18.84 & 34.94 \\
\hline
\end{tabular}

Note: LC- Low Country, MC- Mid Country and UC- Up Country

$L^{*}$ : lightness, $a^{*}$ : Redness and $b^{*}$ : Yellowness

There was also no significant difference found for the colour values of instant tea powder produced from different BMF obtained from the three different elevations. According to Nadeem et al. (2011), the darker colour in instant tea powder is due to the non-enzymatic browning reactions which can occur during the spray drying. Caramelization during the spray drying is another reason for the changes in colour of the instant tea powder.

Caffeine contents were also not significantly different among elevation categories. This may be due to the course nature of BMF which is more or less similar in quality wise among estates of all elevation categories being the poorest grade. However, Harbowy et al. (2010) reported that the caffeine content of tea infusion may vary due to the clone, season, and stage of plucking, geographical locations, harvesting time and infusion conditions of the tea.

\section{Haze in BMF and instant tea powder}

Haze measures the cloudiness or turbidity of the liquid sample. If the turbidity is high, the haze value goes up. Usually, less turbid (clear) liquid is preferred for ready to drink tea beverages. Haze or turbidity is an important parameter which determines the clarity of a drink and a major parameter in making ready to drink tea beverages. Lesser haze values imply higher liquid clarity. Haze values were significantly higher $(\mathrm{p}<0.05)$ in up country BMF (38.50 Nephelometric Turbidity Units (NTU)) compared to the low-country (14.1 NTU) and mid country (14.9 NTU) (Figure 3a).

Haze values were also significantly different among elevation categories (Figure 3b). The instant tea infusion obtained from the up country estates recorded higher values whereas low and mid country instant tea infusions have shown lower values. Results revealed that higher clarity can be obtained from the low country instant tea. According to Arachchilage et al. (2015), higher thearubigins/theaflavin ratio of instant tea can be the reason for the higher turbidity in the upcountry instant tea infusions. The mean haze values of low country (65.63 NTU) and mid country (59.23 NTU) were significantly lower than that of up country instant tea powder, which had the highest haze value (137.9 NTU). In general, the haze values of instant tea were about 4 folds higher than the values obtained from BMF in the respective elevation categories. 
(a)

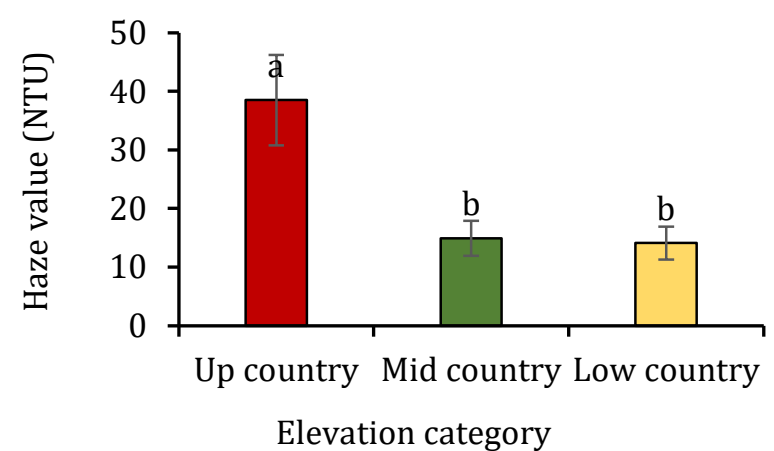

Figure 3: Variation of mean haze values of (a) BMF, and (b) instant tea powder produced using BMF of different elevation categories.

\section{Moisture content and pH of BMF and instant tea}

Moisture contents of the BMF of all three elevation categories were lower than $10 \%$ (Table 3), which is the commercially accepted level for instant tea industry. There were no significant variations observed in moisture content and $\mathrm{pH}$ of BMF among the three elevations. Othieno and Owuor (1984) reported that black tea with moisture content lower than $2.5 \%$ has a burnt flavour due to excessive drying, while tea with a moisture content of greater than $6.5 \%$ is susceptible to chemical and microbiological damage.

The ideal moisture content for post drying was reported as 3-5 \% (Millin, 1985; Özdemir, 1992). However, BMF being a leftover of the black tea production, it always gets less attention at storing which usually causes for higher moisture content.

Results in the Table 3 showed that the moisture content of the instant black tea powders of all elevation categories ranged between $1.56 \pm 0.76$ and $2.60 \pm 0.97$. These instant tea types had moisture contents and $\mathrm{pH}$ levels within the acceptable ranges, which provide better stability to powder during packaging and storage. (b)

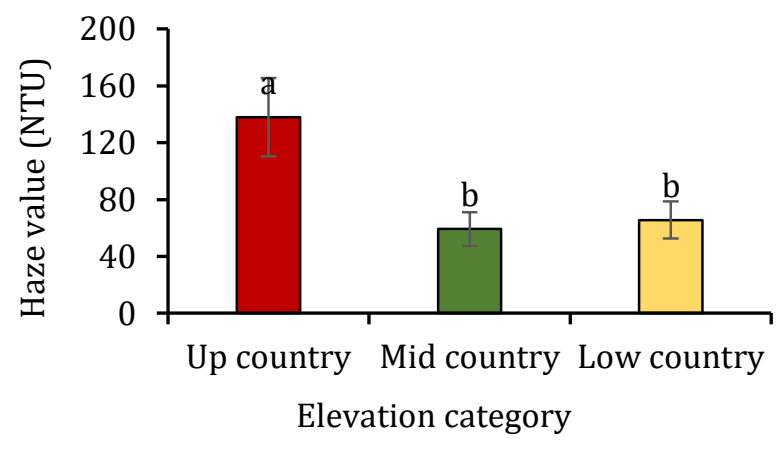

When comparing to the commercially produced instant tea samples, the samples obtained in this study had low moisture contents. The reported low amount of moisture in tested samples may be due to the high inlet air temperature of the miniature spray drier. During the commercial production, the moisture content of the spray-dried powders is usually higher than the above value because of the less inlet and outlet air temperatures compared to miniature spray dryer.

Results of this study showed that the $\mathrm{pH}$ values of BMF obtained from all three elevations are in slightly acidic range which is inherent for tea and it has shown the same trend in the instant tea powder as well. There was no significant difference in $\mathrm{pH}$ amongst all three elevation categories for both BMF as well as instant tea powder.

\section{Comparison of TAA and TPC between $B M F$ and instant tea powder}

Averages across different BMF samples which were used as raw materials to manufacture instant tea powder showed that there was a significant increase $(p<0.05)$ in TAA and TPC contents in instant tea. As per the Figure 4a, it was interesting to note that, the TAA contents were increased by three-fold (112.5 mmol Trolox Equivalents (mMTE)/g in BMF and 336.4 
mMTE/g in Instant Tea powder) and TPC percentages increased by two-fold $(16.88 \%$ in BMF and $32.25 \%$ in Instant tea) in instant tea powder compared to the BMF (Figure $4 \mathrm{~b})$. The increased TPC and TAA contents observed in instant tea powder may be due to the concentration of extractions when instant tea is produced.

Table 3: Moisture content and $\mathrm{pH}$ values of BMF and instant tea produced using the same BMF obtained from different elevation categories.

\begin{tabular}{lcccc}
\hline \multirow{2}{*}{ Estate } & \multicolumn{2}{c}{ Moisture content (\%) } & \multicolumn{2}{c}{$\mathbf{p H}$} \\
\cline { 2 - 5 } & BMF & Instant tea & BMF & Instant tea \\
\hline Deniyaya (MC) & 6.99 & 1.90 & 6.67 & 4.53 \\
Sogama (MC) & 9.05 & 2.60 & 4.40 & 4.38 \\
Kelani (LC) & 3.56 & 1.56 & 4.47 & 4.46 \\
Halgolla (LC) & 8.89 & 2.09 & 4.55 & 4.45 \\
Moragalla (LC) & 6.93 & 1.57 & 4.74 & 4.44 \\
Somerset (UC) & 4.49 & 2.41 & 6.61 & 4.48 \\
Ingestre (UC) & 4.20 & 2.56 & 4.33 & 4.50 \\
N'Eliya (UC) & 5.46 & 2.39 & 4.61 & 4.39 \\
Pedro (UC) & 8.43 & 1.87 & 4.77 & 4.67 \\
Robgill (UC) & 5.09 & 1.92 & 4.82 & 4.49 \\
\hline
\end{tabular}

(a)

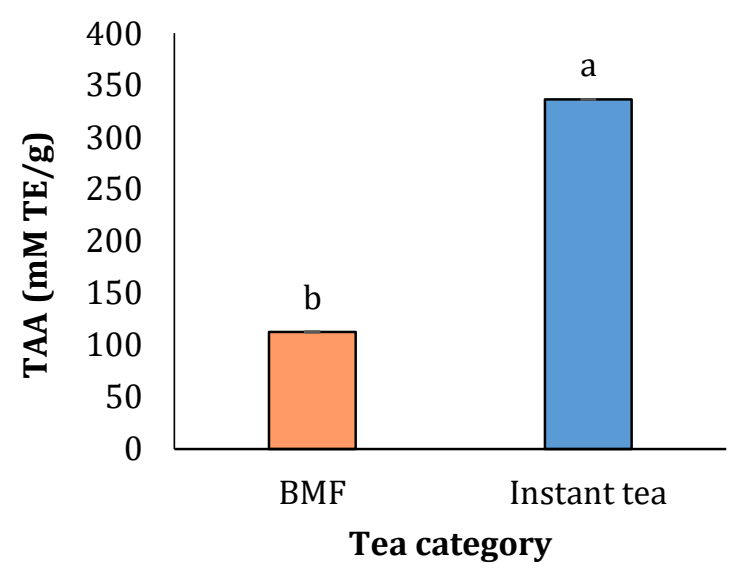

(b)

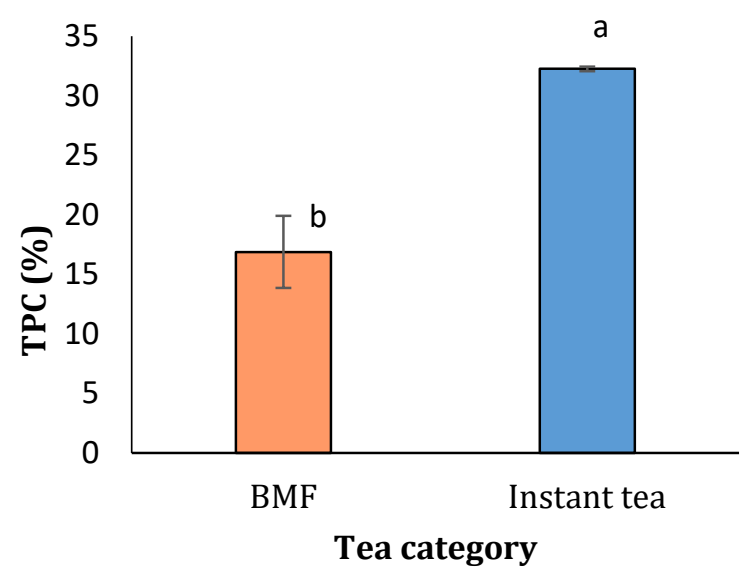

Figure 4: Contents of (a) TAA and (b) TPC in BMF and instant tea powder produced from the BMF

\section{CONCLUSIONS}

Present study was performed to assess the quality variations of (1) BMF obtained predominantly from the cultivar TRI-2025 of different elevation categories as the raw material for producing instant tea powder and (2) instant tea manufactured using this BMF. TAA and TPC contents in BMF across different estates among elevation categories were not significantly different. However, the colour of the tea liquor decreased with 
the increasing elevation. The caffeine content and colour of tea liquor were also not significantly different among elevation categories. However, the haze value of instant tea produced from up country BMF was significantly higher compared to other two elevation categories. Some important quality parameters such as haze of instant tea types produced from BMF varied in

\section{REFERENCES}

Alexander, Y., Yashin Y. and Nemzer, B. (2011). Determination of Antioxidant Activity in Tea Extracts and Their Total Antioxidant Content. The American Journal of Biomedical Science. 3(4), 322-355.

Arachchilage, G.R., Amarakoon, A.M.T., Illeperuma, D.C.K. and Muthukumarana, P.K.P. (2015). Effects of raw material on the chemical composition, organoleptic properties, antioxidant activity, physical properties and the yield of instant black tea. LWT-Food Science and Technology. 63(1), 745-750.

Astill, C., Birch, M.R., Dacombe, C., Humphrey, P.G. and Martin, P.T. (2001). Factors affecting the caffeine and polyphenol contents of black and green tea infusions. Journal of Agricultural and Food Chemistry. 49(11), 5340-5347.

Brand-Williams, W., Cuvelier, M. E. and Berset, C. L. W. T. (1995). Use of a free radical method to evaluate antioxidant activity. LWT-Food Science and Technology. 28(1), 25-30.

Chen, H., Zhang, Y., Lu, X. and Qu, Z. (2012). Comparative studies on the physicochemical and antioxidant properties of different tea extracts. Journal of Food Science and Technology. 49(3), 356-361.

Deb, S. and Pou, K.J. (2016). A review of withering in the processing of black different elevation categories. There was an increase of TAA ( 3 fold) and TPC ( 2 fold) contents and Haze value ( 4 fold) when the instant teas were produced from BMF. This would indicate the possibility of formulating instant tea products for customer preference by selecting appropriate combinations and proportions of raw materials.

tea. Journal of Biosystems Engineering. 41(4), 365-372.

Dufresne, C.J. and Farnworth, E.R. (2001). A review of latest research findings on the health promotion properties of tea. The Journal of Nutritional Biochemistry. 12(7), 404-421.

Groisser, D.S. (1978). A study of caffeine in tea. I. A new spectrophotometric micro-method. II. Concentration of caffeine in various strengths, brands, blends, and types of teas. The American Journal of Clinical Nutrition. 31(10), 1727-1731.

Harboway, M.E., Balentien, D.A., Davies, A.P. and Cai, Y. (2010) Tea Chemistry. In: Critical Reviews in Plant Sciences. Taylor and Francis, New Jersey. pp. 415-480.

ISO (1990), Instant tea in solid form Determination of moisture content (loss in mass at 103 degrees C), ISO 7513, ISO Central Secretariat, International Organization for Standardization, Geneva, Switzerland.

ISO (2005), Determination of substances characteristics of green and black tea. Part 2: Content of catechins in green tea-Method using high-performance liquid chromatography. ISO 14502-2, ISO Central Secretariat, International Organization for Standardization, Geneva, Switzerland. 
Kamal, R.J., Wadood, A.W.M.R and Silva, K.D.R.R. (2008), Total antioxidant capacity of selected grades of black tea growing in different geographical elevations in Sri Lanka, Tropical Agricultural Research. 20, 155-161.

Lesschaeve, I. and Noble, A.C. (2005). Polyphenols: factors influencing their sensory properties and they're affecting on food and beverage preferences. The American Journal of Clinical Nutrition. 330-335.

Liang, Y., Lu, J., Zhang, L. and Wu, S. (2003) Estimation of black tea quality by analysis of chemical composition and colour difference of tea infusions. Journal of Food Chemistry. 80, 283290.

Lunkes, L.B.F. and Hashizume, L.N. (2014). Evaluation of the $\mathrm{pH}$ and titratable acidity of teas commercially available in Brazilian market. RGO-Revista Gaúcha de Odontologia. 62(1), 59-64.

Millin, D.J. (1985). Polyphenols, fermentation and quality. In: Bulletin of United Planters' Association of South India, Tea Science Department, pp. 65-78.

Modder, W.W.D. and Amarakoon, A.M.T. (2002). Tea and health (1 ${ }^{\text {st }}$ Edition). Tea Research Institute, Thalawakelle, Sri Lanka.

Nadeem, H.S., Torun, M. and Özdemir, F. (2011). Spray drying of the mountain tea (Sideritis stricta) water extract by using different hydrocolloid carriers. LWT-Food Science and Technology. 44(7), 1626-1635
Nissanka, S.P., Wanasinghe, W.M.D.N. and Wijeratne, M.A. (2013). Effect of temperature variation on quality parameters of black tea (Camellia sinensis L.) produced in Sri Lanka. In: Proceedings of Climate Change Impact and Adaptations for Food and Environmental Security, 30-31 July 2013. 115-124.

Othieno, C. and Owuor, P. (1984). Black tea quality and international standards. International Tea Journal. 7, 27-30.

Ozdemir, F., Gokalp, H.Y. and Nas, S. (1992). Influence of flushing period, different times within each flushing period and different processing methods on some quality parameters of black tea. Tea Journal. 13, 138-147.

Someswararao, C. and Srivastav, P.P. (2012). A novel technology for production of instant tea powder from the existing black tea manufacturing process. Innovative Food Science and Emerging Technologies. 16, 143-147.

Song, R., Kelman, D., Johns, K.L. and Wright, A.D. (2012). Correlation between leaf age, shade levels, and characteristic beneficial natural constituents of tea (Camellia sinensis) grown in Hawaii. Food Chemistry. 133, 707-714.

Sri Lanka Tea Board (2016). Statistical Bulletin. Sri Lanka Tea Board, 574. Galle Road. Colombo 3.

Sri Lanka Tea Board Annual Report (2015). (online) available at; http://www.srilankateaboard.lk. Accessed on 14/03/2020 